\title{
The Effect of Oral Processing on the Viscosity of Thickened Drinks for Patients With Dysphagia
}

\author{
Katleen J. R. Vallons, $\mathrm{PhD}^{1}$, Lizette A. A. C. M. Oudhuis, $\mathrm{PhD}^{1,2}$, \\ Harold J. Helmens, Msc ${ }^{1,2}$, Cor Kistemaker, Ing $^{3}$ \\ ${ }^{1}$ TNO Food and Nutrition, Zeist; ${ }^{2}$ AVEBE U.A., Veendam; ${ }^{3}$ TNO Triskelion B.V., Zeist, The Netherlands
}

Objective To determine whether a gum-containing thickener maintains its viscosity better during oral processing than a completely starch-based thickener.

Methods Thirty-five healthy volunteers participated in a double-blind, cross-over study. Artificial tap water was thickened to honey-like consistency (effective viscosity of $1,300 \pm 100 \mathrm{mPa} \cdot \mathrm{s}$ at a shear rate of 50 per second at $20^{\circ} \mathrm{C}$ ) with a starch-based thickener (SB) or a gum-containing thickener (GC). Bolus viscosity was determined after standardized oral processing of the thickened water by the subjects for 10 and 20 seconds. Significant effects were determined by ANOVA analysis and pairwise comparisons.

Results Both thickeners were susceptible to breakdown during oral processing. However, GC-thickened water retained its viscosity significantly better than SB-thickened water.

Conclusion The presence of gums has a protective effect on the starch hydrolysis by salivary amylase in thickened drinks, which may facilitate safer swallowing.

Keywords Dysphagia, Saliva, Amylases, Tara gum, Thickener

\section{INTRODUCTION}

Dysphagia is defined as difficulty or inability to swallow. Underlying conditions may be physical, cognitive, or neurological and include stroke, head and neck or esophageal cancer, dementia, and multiple sclerosis [1]. Inadequately managed dysphagia places patients at risk for aspiration, pneumonia, malnutrition and dehydration [2].

Received April 1, 2015; Accepted May 20, 2015

Corresponding author: Katleen J. R. Vallons

TNO Food and Nutrition, Utrechtseweg 48, 3704 HE Zeist, The Netherlands Tel: +31-88-866-2290, Fax: +31-88-866-2879, E-mail: katleen.vallons@tno.nl

(c) This is an open-access article distributed under the terms of the Creative Commons Attribution Non-Commercial License (http://creativecommons. org/licenses/by-nc/4.0) which permits unrestricted noncommercial use, distribution, and reproduction in any medium, provided the original work is properly cited.

Copyright @ 2015 by Korean Academy of Rehabilitation Medicine
In the management of dysphagia, modified-texture foods and thickened fluids are often prescribed by a speech and language therapist (SLT) to ensure safer transfer of nutrition/hydration from the mouth to the stomach. Increasing the viscosity of fluids is a commonly applied approach since it results in longer transit times. This gives the patient more bolus control and time to prepare for the onset of the pharyngeal swallow, and to engage airway-protective mechanisms, thereby decreasing the risk of aspiration $[3,4]$. On the other hand, too high food viscosities may result in bolus residue within the pharyngeal cavity after swallowing, material that could be aspirated at a later stage [5]. Furthermore, patients may reject products with too high a viscosity, which can result in dehydration and malnutrition [6]. Therefore, bolus viscosity should be defined within a relatively narrow range. 
Many of the commercially available powder thickeners for the management of dysphagia contain starch or starch-based products (such as modified maize starch and maltodextrin) as the main ingredient [7]. Human saliva contains $\alpha$-amylase, an endo-enzyme that catalyzes the hydrolysis of $\alpha-1,4$-glycosidic bonds in starch to produce short oligosaccharides. The mechanical structure achieved by starch-based thickeners could be broken down on contact with amylase containing human saliva, resulting in reduced viscosity of the thickened drink. Consequently, the patient may not receive the consistency prescribed by the SLT [8].

Some thickening products used in clinical practice comprise starch along with one or more gums [7]. Gums are not susceptible to the action of salivary $\alpha$-amylase. Therefore, gum-containing thickeners are hypothesized to be less sensitive to the action of amylase and are thought to enhance the safety of swallowing by dysphagia patients $[8,9]$. Hanson et al. [8] recently studied the effect of saliva on the viscosity of different types of drinks thickened with gum-containing thickeners in comparison to standard starch-based thickeners in 2 in vitro experiments. They reported that the thickener composed of gums and starch showed a significant reduction in viscosity in contact with human saliva but retained a certain level of thickness, while the thickener based on starch alone almost completely lost its structure. The saliva used in their study was collected from 2 male individuals and the $\alpha$-amylase activity of the saliva was not described. It is well known that $\alpha$-amylase activity in human saliva shows significant inter- and intra-individual variation $[10,11]$ and is influenced by factors such as age, gender and stress. Another in vitro study using standardized human saliva of known amylase activity indicated that drinks thickened with a gum-containing thickener had significantly better maintenance of consistency following contamination with human saliva, as compared to a standard starch-based thickener [9]. As far as we are aware, no human study on the effect of saliva on the viscosity of drinks thickened with a gum-containing thickener has been conducted. Such a study would confirm and extend the findings of the in vitro studies described above $[8,9]$.

The aim of the present study was evaluate the effect of saliva on the viscosity of a drink thickened with a gumcontaining powder during the oral preparatory phase in humans. The gum based thickener was composed of a mixture of starch and 3 gums (tara, xanthan, and guar gum) and for comparison, a standard starch-based thickener was used. Healthy individuals were given artificial tap water thickened to honey-like consistency and the bolus viscosity after oral processing was determined.

\section{MATERIALS AND METHODS}

\section{Materials}

The 2 thickeners used were an entirely starch-based thickener (SB; Hormel Health Labs Inc., Austin, MN, USA) and a thickener composed of starch and a mixture of tara gum, xanthan gum, and guar gum (GC; Nutricia N.V., Zoetermeer, The Netherlands). The latter was kindly provided by the manufacturer. Both thickeners were powdered and contained modified corn starch. It might be that the composition of both thickeners changes over time due to alterations by the manufacturer. Moisture content of the thickeners was determined in duplicate according to the International Association for Cereal Chemistry (ICC) standard 110/1, adapted to 2.5 hours drying at $130^{\circ} \mathrm{C}$.

\section{Preparation of thickened drinks}

Thickened drinks were prepared by adding thickener to artificial tap water, defined as water with 10 German hardness (DH, $\left.0.2631 \mathrm{~g} / \mathrm{L} \mathrm{CaCl}_{2} \cdot \mathrm{H}_{2} \mathrm{O}\right)$. Drinks were thickened to honey-like consistency (National Dysphagia Diet) [12] defined as an effective viscosity of $1,300 \pm 100$ $\mathrm{mPa} \cdot \mathrm{s}$ at a shear rate of 50 per second at $20^{\circ} \mathrm{C}$. The amount of thickener needed to obtain this viscosity was estimated based on the product's labeling, and the viscosity was evaluated using a Rapid Visco Analyzer type-4 (RVA; Perten Instruments GmbH, Hagersten, Sweden). The estimated amount of thickener $( \pm 0.001 \mathrm{~g})$ was added to $20 \pm$ $0.02 \mathrm{~g}$ of artificial tap water in an aluminum RVA cup. The temperature was set at $20^{\circ} \mathrm{C}$. The measurement was started by stirring at $960 \mathrm{rpm}$ for 10 seconds followed by 500 rpm for 50 seconds to obtain a homogeneous mixture of thickener and water. Subsequently, the effective viscosity at $160 \mathrm{rpm}$ was determined (every 4 seconds) for $15 \mathrm{~min}$ utes. According to Lai et al. [13] the average shear rate at this rotational speed in the RVA is about 53.5 per second. The amount of thickener used was based on the viscosity after 11 minutes, as indicated by the Thermocline software (Perten Instruments). The amount of thickener was 
adjusted until the desired viscosity was obtained.

\section{Study design}

In order to determine the effect of oral processing on the consistency of thickened drinks, a double-blind cross-over study was performed in which 35 healthy adult volunteers participated. The group of volunteers consisted of 12 young females, 15 old females, 2 young males and 6 old male subjects (young $<45$ years of age; old $\geq 45$ years of age). All participants provided written consent to participate in the study and reported no history of swallowing problems. In this study, we used artificial tap water thickened with 2 different thickeners (SB and GC) that was held in the mouth for 10 or 20 seconds. Mandel et al. [10] reported that for healthy subjects, manipulations of a starchy food in the mouth takes 5 seconds for liquids and 10 seconds for semi-solid foods. Kim and Han [14] showed that stroke patients with dysphagia need about twice as much time to prepare a bolus for swallowing. Therefore, the most relevant data are to be expected within the first 20 seconds, hence, bolus viscosity was determined after 10 and 20 seconds.

The study design layout for 4 subjects, representing the balancing realized by reversing treatment order, was given in Table 1. Each subject participated in 2 measurement sessions on separate days. The first test day included a training session of movements of product between tongue and palate and the actual test. During the training session, a droplet of active carbon solution was added on top of the product in order to check whether all panelists moved their tongue effectively. During each measurement session, both products i.e., SB and GC, were tested at 'in mouth' time point 10 seconds and in reverse order at time point 20 seconds within each subject. The test was repeated on the second day, but the products were offered in a different treatment time order than the first day. This resulted in a total of 280 observations $(35 \times 8)$. Subjects were not allowed to eat, drink or smoke for 1 hour before the evaluation.

In each test, the subject was served $10 \mathrm{~g}$ of freshly prepared product after flushing the mouth with water. The tongue was moved at approximately 1 rotation/s by rolling it from the under-teeth to the palate and back. After 10 or 20 seconds, the bolus was spat into a cup containing $1 \mathrm{~mL}$ of $0.2 \mathrm{M} \mathrm{HCl}$. The sample was thoroughly mixed to inactivate the salivary amylase and the closed cup was stored at $-20^{\circ} \mathrm{C}$. Five reference samples of each GC- and SB-thickened types of drink were taken during the sessions (at $\mathrm{t}=0$ ). To each sample, $1 \mathrm{~mL}$ of $0.2 \mathrm{M} \mathrm{HCl}$ was added, after which they were mixed and stored at $-20^{\circ} \mathrm{C}$.

\section{Determination of the viscosity of samples after oral processing}

Viscosity measurements of thawed, masticated and reference samples were performed in a Rheometrics Rheomat RM-180 rotational rheometer. The rheometer was equipped with a Couette-DIN geometry having a cup diameter of $33.87 \mathrm{~mm}$, a bob diameter of $31.98 \mathrm{~mm}$, and bob height of $33.08 \mathrm{~mm}$. The measurements were performed at $20^{\circ} \mathrm{C}$, with constant shear rate of 50 per second, and viscosities were obtained after 300 seconds of shear. In total, 290 samples were analyzed $(35 \times 2 \times 4=280+10$ references).

Relative viscosities were calculated as the ratio of the viscosity of the spat samples over the average viscosity of the reference sample, expressed as a percentage.

\section{Statistical analysis}

Differences in relative viscosities between treatment times 10 seconds and 20 seconds or between products, were analyzed by ANOVA using PROC GLM (SAS V9.1.3 Service pack 4), resulting in Type III partial effect tests

Table 1. Study design layout for 4 subjects, representing the balancing realized by reversing treatment order

\begin{tabular}{lcccccccc}
\hline & \multicolumn{3}{c}{ Day 1 } & \multicolumn{4}{c}{ Day 2} \\
\hline Treatment time (s) & 10 & 20 & 20 & 10 & 10 & 20 & 20 & 10 \\
Subject ' $i$ ' & A-B & B-A & & & & & B-A & A-B \\
\hline Subject ' $j$ ' & B-A & A-B & & & & & A-B & B-A \\
Subject ' $k$ ' & & & A-B & B-A & B-A & A-B & & \\
\hline Subject ' $l$ ' & & & B-A & A-B & A-B & B-A & \\
\hline A & & & &
\end{tabular}

A and B represent the 2 different thickeners used. 
(corrected for all other effects in the model). PROC MIXED was used for the estimation of the effect means and for the pairwise comparison (Method: REML, Satterthwaite degreed of freedom estimates). Pairwise comparisons were performed to study individual contrasts. A bonferroni correction was performed to counteract for multiple comparisons.

\section{RESULTS}

Water was thickened to honey-like consistency by addition of $6.3 \mathrm{~g} / 100 \mathrm{~g}$ and $6.0 \mathrm{~g} / 100 \mathrm{~g}$ of SB and GC, respectively, as determined by RVA. The viscosity of the thickened drinks was expressed as relative viscosity (\%), which was defined as the ratio of the viscosity after oral processing to the viscosity before oral processing. The viscosities before oral processing were $1315 \pm 364 \mathrm{mPa} \cdot \mathrm{s}$ and 1,376 $\pm 252 \mathrm{mPa} \cdot \mathrm{s}$. for SB- and GC-thickened drinks, respectively.

\section{Effect of time}

Table 2 showed the mean estimates and errors for the relative viscosity after 10 seconds and 20 seconds across both products. The relative viscosity of the thickened water decreased during oral processing, with a significantly lower viscosity after 20 seconds, as compared to the viscosity after 10 seconds $(\mathrm{p}<0.001)$.

\section{Effect of product}

Table 2 showed that the relative viscosity as a function of product was significantly higher for GC-thickened water (52.9\%), as compared with SB-thickened water (20.3\%) $(\mathrm{p}<0.001)$.

Table 2. Comparison of relative viscosity as a function of time and product

\begin{tabular}{ccc}
\hline & Relative viscosity (\%) & p-value \\
\hline Time (s) & & \\
10 & $43.9 \pm 3.4$ & $<0.001$ \\
20 & $29.3 \pm 3.4$ & $(10$ s vs. 20 s) \\
Product & & \\
SB & $20.3 \pm 3.4$ & $<0.001$ \\
GC & $52.9 \pm 3.4$ & (SB vs. GC) \\
\hline
\end{tabular}

Values are presented as least squares mean estimates \pm errors.

SB, starch-based thickener; GC, gum-containing thickener.
The results of pairwise comparisons of the viscosities after 10 seconds and 20 seconds were shown in Fig. 1. After 10 seconds of oral processing, the viscosity of the SB-thickened water was $383.6 \mathrm{mPa} \cdot \mathrm{s}$ and the viscosity of GC thickened water was $901.1 \mathrm{mPa} \cdot \mathrm{s}(\mathrm{p}<0.01)$. During prolonged oral processing, the viscosity decreased to $187.0 \mathrm{mPa} \cdot \mathrm{s}$ and $616.4 \mathrm{mPa} \cdot \mathrm{s}$ after 20 seconds for SB and GC thickened water, respectively $(\mathrm{p}<0.01)$. This result indicated that at 20 seconds, the viscosity decreased from honey-like viscosity to nectar-like viscosity in the SB thickened drink, but not the GC thickened water.

\section{DISCUSSION}

The current study results indicated that both SB and GC thickener are susceptible to breakdown during oral processing. However, GC-thickened water retained its viscosity significantly better after oral processing than SBthickened water.

Clinical practice of dysphagia management is strongly dependent on texture/viscosity modification and a significantly lower viscosity during swallowing impairs the safety of swallowing.

The observed difference in viscosity during oral processing between both drinks suggested a difference in sensitivity to structure breakdown during oral processing. It has been shown that drinks thickened with starch

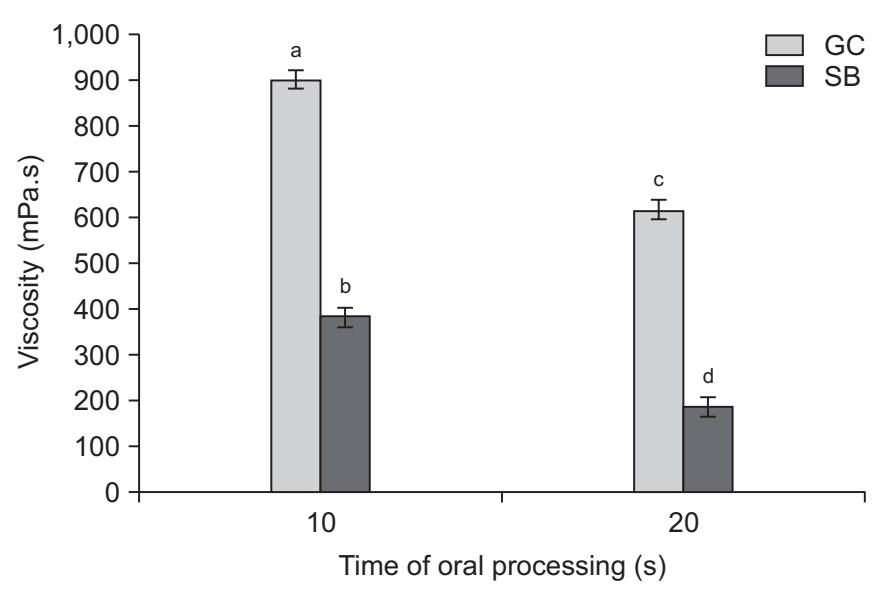

Fig. 1. Viscosity (mPa.s) of starch-based (SB) and gumcontaining (GC) thickener after 10, and 20 seconds of oral processing. The mean estimates and errors of the ANOVA analysis are shown. Significant differences $(p<0.01)$ obtained from pairwise comparisons are indicated by letters. 
undergo thinning when in contact with saliva due to the action of salivary amylase, which breaks down the starch $[8,9]$. Our results indicated a protective effect of gums on the breakdown of consistency of the thickened drink by salivary amylase. Several authors have previously observed a decrease in amylase activity in the presence of gums and reported various factors that might play a role in this inhibitory effect. Firstly, Brennan et al. [15] reported that guar gum may act as a physical barrier during starch digestion by forming a layer around starch granules, shielding them from enzyme attack. Secondly, hydrophilic gums might limit the availability of water needed for the hydrolysis of the glycosidic linkages in starch [16]. Finally, Slaughter et al. [16] concluded that galactomannan acts as a non-competitive inhibitor of $\alpha$-amylase, by direct binding of $\alpha$-amylase to galactomannan and the resulting galactomannan-amylase complex is inactive. In addition to the inhibitory effects of gums on amylase activity, the higher relative viscosity found for the GC-thickened tap water compared to starch-thickened water can also be explained by the thickening effect of the gums. As amylase only breaks down the starch component of the mixture, the water is still be thickened by the gum. This is in agreement with the results of a study by Hanson et al. [8], which showed that saliva reduced the viscosity of water thickened with starch almost $100 \%$, whereas the thickener composed of starch and gums retained a level of thickening. Further research is needed to determine the relative importance of the different gum-related mechanisms for the improved stability in consistency of drinks thickened with starch-gum mixtures.

A limitation of the current study was the study population that consisted of healthy volunteers, rather than patients with dysphagia. The disease state and medication used by patients with dysphagia may influence the amount and composition of saliva produced and thereby the effect of oral processing on viscosity of thickened drinks. Furthermore, clinically relevant aspects such as the degree to which a subject is able to mix a bolus with saliva and the duration of the oral preparatory phase may differ between healthy and dysphagia subjects. Furthermore, by using a standardized way of oral processing of 1 rotation/s, individual differences in mastication frequency were not taken into account in the current study.

As discussed above, a significant lower viscosity during swallowing could impair the safety of swallowing, since the patient does not receive the prescribed consistency. More research is needed to determine the effect of consistency breakdown during oral processing on the safety of swallowing in dysphagia patients, and to confirm the increase in swallowing safety when gum-containing thickeners are used. Furthermore, studies are required to determine whether the extent of variation in amylase sensitivity of thickeners has an impact on aspiration, on the amount of oral residue formed, and on the stability in consistency of the residue formed.

While not addressed in this study, characteristics other than amylase sensitivity could influence the viscosity of a thickened drink and consequently the safety of swallowing. For instance, the type of thickener used, the time allowed to thicken and the type of liquid influence the viscosity of a thickened drink [17]. Also, a difference in viscosity between thickened fluids categories (like nectar, honey) used in videofluoroscopic evaluation of dysphagia and the correspondingly named thickened drinks used for therapy can affect the safety of swallowing in patients with dysphagia $[18,19]$.

In conclusion, this study showed that oral processing resulted in a decreased viscosity of thickened drinks. However, water thickened with a gum-containing product retained its viscosity significantly better, as compared to a starch-based product. Clearly, the presence of gums has a protective effect on the starch hydrolysis by salivary amylase in thickened drinks, which facilitates safer swallowing.

\section{CONFLICT OF INTEREST}

No potential conflict of interest relevant to this article was reported.

\section{ACKNOWLEDGMENTS}

The authors wish to acknowledge the financial support received from Nutricia Research, The Netherlands. They also wish to thank Dr. Edward Sliwinski and Dr. Mirian Lansink for their expert advice throughout the project, Dr. Albert Jurgens for his knowledge input during the preparation of this paper and Dr. Eric Schoen and Dr. Sabina for their assistance with the statistical analysis. 


\section{REFERENCES}

1. Leslie P, Carding PN, Wilson JA. Investigation and management of chronic dysphagia. BMJ 2003;326:433-6.

2. Logemann JA. Evaluation and treatment of swallowing disorders. Austin: Pro-Ed; 1998.

3. Kuhlemeier KV, Palmer JB, Rosenberg D. Effect of liquid bolus consistency and delivery method on aspiration and pharyngeal retention in dysphagia patients. Dysphagia 2001;16:119-22.

4. Logemann JA, Gensler G, Robbins J, Lindblad AS, Brandt D, Hind JA, et al. A randomized study of three interventions for aspiration of thin liquids in patients with dementia or Parkinson's disease. J Speech Lang Hear Res 2008;51:173-83.

5. Clave P, Arreola V, Romea M, Medina L, Palomera E, Serra-Prat M. Accuracy of the volume-viscosity swallow test for clinical screening of oropharyngeal dysphagia and aspiration. Clin Nutr 2008;27:806-15.

6. Cichero JA, Murdoch BE. Dysphagia: foundation, theory and practice. Chichester: John Wiley \& Sons; 2006.

7. Smith A. Dysphagia product update. NHD Dietit Mag 2013;88:23-6.

8. Hanson B, O'Leary MT, Smith CH. The effect of saliva on the viscosity of thickened drinks. Dysphagia 2012; 27:10-9.

9. Vallons KJ, Helmens HJ, Oudhuis AA. Effect of human saliva on the consistency of thickened drinks for individuals with dysphagia. Int J Lang Commun Disord 2015;50:165-75.

10. Mandel AL, Peyrot des Gachons C, Plank KL, Alarcon $\mathrm{S}$, Breslin PA. Individual differences in AMY1 gene copy number, salivary $\alpha$-amylase levels, and the perception of oral starch. PLoS One 2010;5:e13352.
11. Rohleder N, Nater UM. Determinants of salivary alphaamylase in humans and methodological considerations. Psychoneuroendocrinology 2009;34:469-85.

12. National Dysphagia Diet Task Force. National dysphagia diet: standardization for optimal care. Chicago: American Dietetic Association; 2002.

13. Lai KP, Steffe JF, Ng PK. Average shear rates in the rapid visco analyser (RVA) mixing system. Cereal Chem 2000;77:714-6.

14. Kim IS, Han TR. Influence of mastication and salivation on swallowing in stroke patients. Arch Phys Med Rehabil 2005;86:1986-90.

15. Brennan CS, Blake DE, Ellis PR, Schofield JD. Effects of guar galactomannan on wheat bread microstructure and on the in vitro and in vivo digestibility of starch in bread. J Cereal Sci 1996;24:151-60.

16. Slaughter SL, Ellis PR, Jackson EC, Butterworth PJ. The effect of guar galactomannan and water availability during hydrothermal processing on the hydrolysis of starch catalysed by pancreatic alpha-amylase. Biochim Biophys Acta 2002;1571:55-63.

17. Garcia JM, Chambers E 4th, Matta Z, Clark M. Viscosity measurements of nectar- and honey-thick liquids: product, liquid, and time comparisons. Dysphagia 2005;20:325-35.

18. Costa MM, Almeida JT, Sant'Anna E, Pinheiro GM. Viscosities reproductive patterns for use in videofluoroscopy and rehabilitation therapy of dysphagic patients. Arq Gastroenterol 2007;44:297-303.

19. Strowd L, Kyzima J, Pillsbury D, Valley T, Rubin B. Dysphagia dietary guidelines and the rheology of nutritional feeds and barium test feeds. Chest 2008;133: 1397-401. 